\title{
ANALISIS PERANCANGAN BUSINESS INTELLIGENCE BERBASIS SAAS CLOUD COMPUTING
}

\author{
I Gede Adnyana \\ Magister Teknik Elektro \\ Universitas Udayana \\ Denpasar, Bali \\ adnyana.nakkuta@gmail.com
}

\begin{abstract}
Abstrak
Persaingan bisnis yang ketat, mendorong setiap perusahaan menyusun strategi bisnis agar dapat bertahan dari para pesaing. Penyusunan strategi bisnis mutlak memerlukan informasi yang tepat dan akurat, pengolahan hingga analisis data yang menghasilkan informasi yang tepat dan akurat menjadi proses yang sangat penting. Business Intelligence (BI) menawarkan solusi bisnis untuk menganalisis data dan memungkinkan suatu perusahaan untuk mengambil keputusan untuk meningkatkan keuntungan dan kinerja bisnis. Namun, $\mathrm{BI}$ mahal untuk diimplementasikan, memerlukan biaya pemeliharaan yang tidak sedikit dan infrastruktur yang kuat. Hal ini mendorong perusahaan mengurangi biaya tetapi masih memiliki teknologi yang tepat untuk memungkinkan mereka untuk membuat keputusan, mengidentifikasi peluang dan proaktif mengidentifikasi risiko yang dapat mempengaruhi bisnis. Konsep Software as a Service (SaaS) Cloud Computing dapat menjawab tantangan yang dihadapi BI. Sebelum merancang BI berbasis SaaS perlu diketahui parameter-parameter evaluasi hingga kelebihan dan kekurangannya.
\end{abstract}

Kata Kunci; Business Intelligence, Software as a Service, cloud computing

Abstract

Tight business competition, pushing each company business strategy in order to survive the competition. Preparation of business strategy requires absolute precise and accurate information, processing to data analysis that produces precise and accurate information becomes very important process. Business Intelligence (BI solutions offer business to analyze the data and allows a company to take decisions to improve profitability and business performance. However, $\mathrm{BI}$ is expensive to implement, requires little maintenance costs and a strong infrastructure. This encourages companies to reduce costs but still have the right technology to enable them to make decisions, identify opportunities and proactively identify risks that may affect the business. The concept of Software as a Service (SaaS Cloud Computing can address challenges faced by BI. Before designing a SaaS-based $\mathrm{BI}$ need to know the parameters to evaluate the advantages and disadvantages.

Keyword: Business Intelligence, Software as a Service, cloud computing 


\section{PENDAHULUAN}

Persaingan bisnis yang ketat, mendorong setiap perusahaan menyusun strategi bisnis agar dapat bertahan dari para pesaing. Selain digunakan untuk bertahan/survive, strategi bisnis juga dimaksudkan agar perusahaan tersebut dapat tumbuh dan menghasillkan profit/keuntungan. Dalam perancangan strategi bisnis, informasi menjadi pondasi dari setiap langkah yang akan diambil. Dukungan dari divisi/bagian Teknologi Informasi (TI) mutlak diperlukan sebagai penyedia informasi yang cepat dan akurat. Informasi tersebut kemudian dimanfaatkan oleh perusahaan untuk menghasilkan proyeksi bisnis yang kemudian dianalisis lebih lanjut agar hasilnya dapat dipahami dan digunakan sebagai dasar pengambilan keputusan

Dalam pengolahan data, beberapa perusahaan sudah menerapkan Enterprise Resource Planning (ERP). Sistem ERP dapat mengintegrasikan transaksi bisnis ke dalam tabel-tabel master untuk perencanaan. Walau suatu perusahaan sudah memiliki sistem ERP, yang dapat menyimpan berbagai data transaksi yang tidak terhitung jumlahnya. Namun ada hal mendasar yang belum tercapai yaitu bagaimana memanfaatkan data tersebut untuk mengambil keputusan cerdas di masa depan. ERP bukanlah sistem yang dapat melakukan analisis data dalam proses pengambilan keputusan. Karena keterbatasannya, maka dibutuhkan suatu sistem yang dapat melakukan pemetaan data ERP dan menghasilan beberapa analisis

Untuk itu dirancang suatu Business Intelligence $(\mathrm{BI})$ yang mampu memberikan beberapa analisis dari data ERP yang digunakan dasar untuk pengambilan keputusan. Dalam BI, informasi diukur dari ketepatan waktu dan relevansinya. Penggunaan sumber daya yang efisien juga menjadi tolak ukur keberhasilan strategi bisnis. Konsep cloud computing menjawab efisiensi sumber daya TI. Dalam tulisan ini, dilakukan analisis perancangan Business Intelligence yang berbasis Software as a
Service (SaaS) yang mampu menghasilkan analisis bisnis yang cerdas dengan sumber daya yang se-efisien mungkin.

\section{Business INTELLIGENCE DAN SAAS CLOUD COMPUTING}

\section{A. Bussiness Intelligence}

Business Intelligence (BI) didefinisikan sebagai alat, teknologi, dan proses yang diperlukan mengubah data menjadi informasi dan informasi menjadi pengetahuan dan rencana yang mengoptimalkan tindakan bisnis [6].

Umumnya teknik yang dipakai dalam BI adalah teknik mengidentifikasi, mengekstrasi dan menganalisis data dari bisnis tertentu berdasarkan kategori atau faktor-faktor yang mempengaruhinya. Secara luas dapat dilihat sebagai informasi bisnis dan proses menganalisis informasi dalam konteks proses bisnis utama yang mengarah pada pengambilan keputusan atau tindakan untuk meningkatkan kinerja bisnis. BI menggabungkan produk, teknologi dan metode yang membantu dalam meningkatkan kinerja bisnis untuk mencapai keuntungan yang maksimal. Adapun fungsionalitas dari BI antara lain [6] :

- Reporting - query, pelaporan dan searching tools

- Analysis - OLAP (On Line Analytical Processing), visualization tools

- Monitoring - dashboard, scorecard

- Prediction - analisis prediktif

Dengan memanfaatkan $\mathrm{BI}$, perusahaan dapat meningkatkan keuntungan yang diperoleh dari pelanggan dan menarik pelanggan, dengan menciptakan program pemasaran yang mencerminkan keunikan dan setiap pelanggan. $\mathrm{BI}$ juga memungkinkan perusahaan untuk memantau perubahan perilaku pelanggan yang bisa memicu tindakan spesifik, hal ini memberi kesempatan kepada perusahaan untuk meningkatkan penjualan per pelanggan dengan memprediksi produk tertentu yang paling mungkin untuk dijual. Hal ini dilakukan dengan menyesuaikan strategi harga untuk melawan persaingan 
dan memaksimalkan keuntungan dan proaktif memonitor, mendiagnosa dan memprediksi kebutuhan layanan pelanggan.

Dalam

penggunaan $\mathrm{Bl}$, suatu perusahaan akan mendapat tantangan sebagai berikut [10] :

- Adanya keperluan mendesak perusahaan untuk mengurangi modal pengeluaran dan biaya operasional.

- Adanya kekurangan ketrampilan yang secara efektif menciptakan dan memelihara solusi analisis bisnis yang dapat memberikan nilai tambah untuk suatu bisnis.

- Bisnis yang ada saat ini menghasilkan volume data yang sangat besar yang berasal dari beberapa sumber termasuk ERP, solusi Customer Relationship Management (CRM), dan log Global Positioning System (GPS).

- Perputaran data yang dihasilkan sangat besar dan tiba setiap hari, jam dan real-time. Hal ini memerlukan mesin yang kuat untuk memproses data untuk mengidentifikasi tren dalam data dan kadang-kadang hanya dapat dieksekusi di malam hari agar tidak mempengaruhi bisnis selama jam kerja.

- Bisnis membutuhkan solusi ondemand untuk analisis penjualan, visibilitas supply chain, analisis pelanggan, merchandising dan analisis produk.

- Dalam hal pengendalian biaya infastruktur menjadi tugas besar untuk memastikan infrastruktur yang tepat tersedia untuk peak times.

- Biaya untuk melaksanakan dan menjaga solusi analisis bisnis mahal

BI menawarkan solusi bisnis untuk menganalisis data dan memungkinkan suatu perusahaan untuk mengambil keputusan untuk meningkatkan keuntungan dan kinerja bisnis. Namun, BI mahal untuk diimplementasikan, memerlukan biaya pemeliharaan yang tidak sedikit dan infrastruktur yang kuat. Hal ini mendorong perusahaan mengurangi biaya tetapi masih memiliki teknologi yang tepat untuk memungkinkan mereka untuk membuat keputusan yang memungkinkan mereka untuk mengidentifikasi peluang dan proaktif mengidentifikasi risiko yang dapat mempengaruhi bisnis. Konsep cloud computing dapat menjawab tantangan yang dihadapi BI.

\section{B. Cloud Computing}

Kata cloud pada cloud computing mengacu pada "Internet". Computing adalah setiap operasi TI dilakukan oleh organisasi. Oleh karena itu secara sederhana cloud computing dapat diartikan " komputasi berbasis internet ", dimana berbagai layanan dalam bentuk server, penyimpanan, berbagi sumber daya dan informasi yang diberikan kepada suatu komputer organisasi dan perangkat lain sesuai permintaan melalui Internet [7].

Cloud computing menyediakan fasilitas untuk mengakses berbagi sumber daya dan infrastruktur umum, menawarkan jasa dan permintaan melalui jaringan untuk melakukan operasi yang memenuhi perubahan kebutuhan bisnis. Lokasi sumber daya fisik dan perangkat yang sedang diakses biasanya tidak diketahui oleh pengguna. [4][6]

Cloud computing dibedakan menjadi tiga model yaitu [1][5]

- Infrastructure as a Service (laaS)

Pengguna dapat menggunakan fundamental computing resources seperti processing power, storage, networking component. Pengguna diijinkan untuk menginstal sistem operasi, storage, membangun aplikasi sendiri, membuat firewall dan load balancer. Contoh laas yaitu Amazon Elastic Compute Cloud.

- Platform as a Sevice (PaaS)

Pengguna dapat mengembangkan aplikasi menggunakan application framework atau application engine yang disediakan oleh provider. 
Pengguna dapat leluasa mengontrol aplikasi, namun tidak dapat mengontrol sistem operasi, hardware, atau network. Contoh PaaS yaitu Force.com dan Microsoft Azure Investment.

- Software as a Service (SaaS)

Pengguna dapat menggunakan aplikasi namun tidak dapat membuat aplikasi, tidak dapat mengontrol sistem operasi, hardware dan network. Aplikasi dapat diakses via web browser atau web based interface. Contoh SaaS adalah GoogleDoc dan SalesForce.

Cloud dapat dibangun sebagai private cloud, yang dibuat hanya untuk lingkungan internal (organisasi tertentu). Jika private cloud dibangun oleh pihak lain (outsourcing/hosting provider) dan server cloud berada di luar organisasi yang akan menggunakannya, maka private cloud semacam ini disebut virtual private cloud. [5]

Jika cloud dapat diakses oleh sembarang pengguna, melalui jaringan Internet, maka cloud semacam ini disebut public cloud. Public Cloud yang dikelompokkan ke dalam beberapa grup berdasarkan interest (misal : profesi, hobi ) yang sama, disebut community cloud atau vertical cloud. Sedangkan cloud yang melibatkan gabungan private cloud dengan public cloud disebut hybrid cloud. [5]

Ada beberapa manfaat dari cloud computing yaitu : [8]

- Skalabilitas, yaitu dengan cloud computing kita bisa menambah kapasitas penyimpanan data kita tanpa harus membeli peralatan tambahan, misalnya hardisk dll. Kita cukup menambah kapasitas yang disediakan oleh penyedia layanan cloud computing.

- Aksesibilitas, yaitu kita bisa mengakses data kapanpun dan dimanapun kita berada, asal kita terkoneksi dengan internet, sehingga memudahkan kita mengakses data disaat yang penting.

- Keamanan, yaitu data kita bisa terjamin keamanan nya oleh penyedia layanan cloud computing, sehingga bagi perusahaan yang berbasis IT, data bisa disimpan secara aman di penyedia cloud computing. Itu juga mengurangi biaya yang diperlukan untuk mengamankan data perusahaan.

- Kreasi, yaitu para user bisa melakukan/ mengembangkan kreasi atau project mereka tanpa harus mengirimkan project mereka secara langsung ke perusahaan, tapi user bisa mengirimkan nya lewat penyedia layanan cloud computing.

- Kecemasan, ketika terjadi bencana alam data milik kita tersimpan aman di cloud meskipun hardisk atau gadget kita rusak

\section{Software as a Service (SaaS)}

Saas adalah model pengiriman perangkat lunak yang memungkinkan ondemand lisensi perangkat lunak [3]. Vendor SaaS bertanggung jawab atas pemeliharaan, operasional sehari-hari dan aplikasi data dari masing-masing pelanggan. Pelanggan tidak perlu direpotkan dengan masalah perawatan dan update aplikasi yang digunakan.

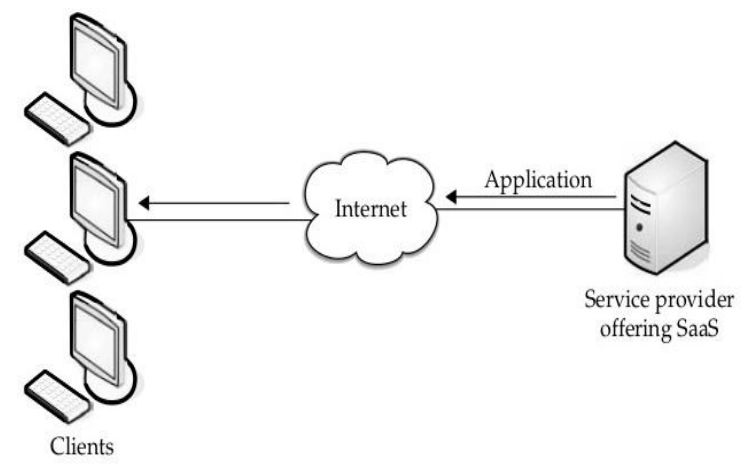

Gambar 1. Ilustrasi Service as a Service (SaaS) 

[3] :

SaaS memiliki beberapa aspek meliputi

- Accessibility

SaaS memungkinkan akses yang konsisten dan sesering mungkin bila diperlukan untuk penggunaan layanan perangkat lunak yang kritis yang mendukung operasi bisnis. Layanan perangkat lunak dapat diakses melalui web browser dan koneksi internet aktif.

- Reliability

Sebagai layanan perangkat lunak yang tersedia di provider, mereka bertanggung jawab atas security dan monitoring. Misalnya untuk mencegah kehilangan data, provider melakukan backup data pelanggan.

- Configurability

Pelanggan Saas dapat menyesuaikan layanan perangkat lunak untuk memenuhi kebutuhan masing-masing. Ini adalah hasil dari fitur sewa multi Saas yang memungkinkan beberapa konfigurasi pelanggan SaaS yang akan digunakan pada layanan perangkat lunak yang sama.

- Scalability

SaaS memungkinkan sumber daya komputasi untuk secara dinamis ditambahkan atau dihapus sesuai kebutuhan konsumen

- Cost

SaaS adalah membayar per layanan penggunaan, tidak ada investasi di server dan biaya lisensi perangkat lunak, yang mengarah ke penghematan biaya $\mathrm{TI}$

- Standardized IT based capability. SaaS mampu memberikan kualitas layanan yang sama seperti yang ada pada vendor perangkat lunak yang on-site

II. Perancangan business intelligence BERBASIS SAAS

Teknologi SaaS yang menyediakan layanan remote akses ke perangkat lunak melalui internet, saat ini mengalami perkembangan bahkan melibatkan produsen ERP/MRP sistem di dunia. Penggunaan konsep SaaS dalam strategi TI yang mendukung strategi bisnis dalam perusahaan memberikan keuntungan karena adanya pengurangan biaya dalam hal pembuatan hingga pemeliharaan perangkat lunak tidak lagi dilakukan oleh perusahaan melainkan dilakukan oleh pihak ketiga. Ada beberapa keuntungan penerapan model SaaS, diantaranya [11] :

- Biaya untuk memulai rendah

- Kecepatan untuk memulai tinggi

- Biaya berlangganan rendah

- Tidak perlunya instalasi perangkat lunak di workstation pengguna

- Akses online dari pengguna ke sistem melalui koneksi internet

- Penghapusan biaya lisensi dan upgrade

- Biaya TCO rendah (Total Cost of Ownership) karena kurangnya perlunya investasi besar dalam server, database dan pemeliharaan

- Akses berkelanjutan ke versi software terbaru yang kompatibel

- Akses ke teknologi bisnis terbaru.

- Penerapan metode modern manajemen strategis

\section{A. Business Intelligence (BI) on Demand}

Dengan penerapan konsep cloud computing, suatu perusahaan dapat menyelesailan permasalahan yang dihadapi dengan penerapan sistem onsite saat ini. Penerapan solusi $\mathrm{BI}$ on demand memungkinkan perusahaan mengurangi biaya operasional dengan beralih ke biaya berlangganan. Solusi $\mathrm{BI}$ on demand mengarah pada solusi SaaS, dimana layanan perangkat lunak disewakan oleh pihak ketiga dengan biaya berlangganan bulanan atau tahunan. Hal ini dapat meningkatkan operasional dan fleksibilitas keuangan dan mengurangi biaya pemeliharaan perangkat lunak. 


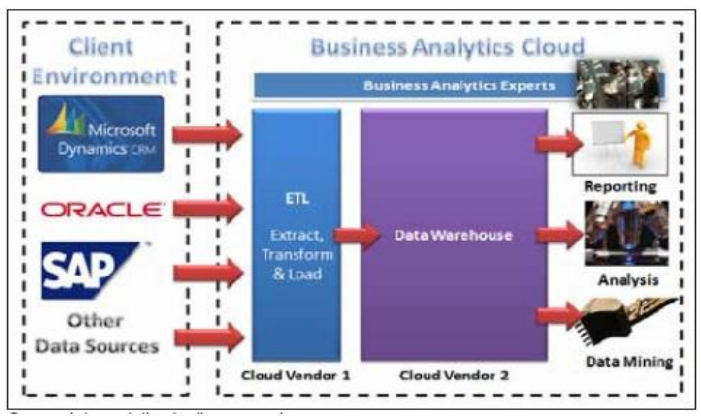

Gambar 2. Business Intelligence on demand

Pada gambar 2, dapat dilihat penerapan solusi BI dengan konsep SaaS. Data transaksi diambil dari lingkungan pengguna kemudian diolah dan disimpan pada data warehouse. Data warehouse dan data mining tool pada lingkungan cloud digunakan untuk penyedia informasi yang berguna untuk menentukan keputusan operasional maupun strategi bisnis.

Data warehouse memberikan kemampun untuk mempelajari prilaku atau tindakan bisnis pada masa lalu, bagaimana keadaan saat ini hingga memberikan prediksi bisnis di masa depan. Perangkat lunak BI mempunyai kemampuan untuk melakukan penelusuran yang memungkinkan pengguna untuk mengakses informasi dalam laporan untuk menemukan rincian yang relevan dari data yang spesifik. Solusi BI SaaS dapat memberikan laporan standar dengan segera begitu perusahaan mengimplementasikan cloud computing dalam bisnisnya. Laporan bisnis biasanya diterbitkan terpusat dan dalam lingkungan yang aman, yang dapat diakses di seluruh dunia.

Mesin OLAP yang dimplementasikan dalam solusi BI SaaS mempercepat analisis data yang kompleks di semua aspek bisnis. Hal ini memungkinkan perusahaan meningkatkan pelaporan untuk penjualan, pemasaran, pelaporan manajemen, manajemen proses bisnis, anggaran dan peramalan, pelaporan keuangan dan bidang lainnya.
Fitur penting dalam solusi BI SaaS adalah dashboard yang memberikan pandangan (view) terhadap informasi bisnis, yang dirancang agar mudah untuk dibaca. Dashboard menggabungkan semua informasi menjadi satu, interface yang mudah digunakan memungkinkan manager secara proaktif mengidentifikasi area permasalahan dan mengambil tindakan yang diperlukan untuk menyesaikan permasalahan tersebut. Dashboard menghemat waktu dengan menjalankan beberapa laporan dan memungkinkan manajer untuk mendapatkan jumlah visibilitas semua aspek dalam bisnis secara langsung [10]

\section{B. Parameter-parameter Evaluasi untuk SaaS Provider}

Dalam pemilihan model SaaS untuk diimplementasikan dalam bisnis, perlu diketahui parameter-parameter yang harus dipertimbangkan selama proses memperkirakan kredibilitas perangkat lunak yang akan disewa dari penyedia layanan. Berikut parameter-parameter yang perlu dipertimbangkan [11]:

1. Keamanan Data, transfer data menjadi hal yang "sensitif" bagi perusahaan. Timbul kecemasan bagi perusahaan bagaimana jika kehilangan data atau data tersebut diambil oleh pesaing bisnisnya. Dalam konteks ini sangat penting memeriksa prosedur keamanan yang dijamin oleh penyedia layanan.

2. Garansi SLA (Service Level Agreements). Ini adalah kontrak di mana penyedia layanan menjamin tingkat layanan dengan ketentuan tertentu. Ini mencakup jaminan efisiensi tinggi, aksesibilitas dan keamanan. Penyedia layanan menjamin jika terjadi server breakdown, kekurangan pasukan listrik atau permasalahan dalam internet, pekerjaan akan langsung diambil alih oleh data center yang sepanjang waktu siap untuk secara otomatis mengambil alih seluruh beban yang dihasilkan oleh pengguna sistem SaaS. 
3. Kemungkinan ekspor data dan cara akses ke arsip data. Perusahaan mungkin ingin bermigrasi dari sistem SaaS. Dalam kasus seperti ini sangat penting untuk mengekspor data ke sistem baru. Hal ini penting untuk diperiksa apakah penyedia layanan mempertimbangkan situasi seperti ini dan apakah mempunyai prosedur migrasi.

4. Kemungkinan impor data. Ini perlu diperiksa apakah data yang sudah dimiliki sebelumnya dapat di impor ke model SaaS

5. Pelaporan parameter. Karena SaaS didasarkan pada remote akses ke data "sendiri" sangat penting disebutkan dalam kontrak SLA untuk memasukkan parameter yang dapat diakses untuk memudahkan melakukan kontrol dan pelaporan yang jelas oleh penyedia layanan

C. Kelemahan Sistem Berbasis SaaS

Selain memiliki beberapa kelebihan yang telah dibahas sebelumnya, sistem berbasis
SaaS juga memiliki beberapa kekurangan diantaranya :

1. Membutuhkan koneksi internet yang kuat.

Meskipun koneksi online tersedia hampir di mana-mana, tingkat koneksi tidak pernah sama. Beberapa daerah tidak dapat menyediakan koneksi internet yang kuat dan SaaS (sebagai online aplikasi) harus memuat segala sesuatu di browser. Fungsi yang diharapkan tidak akan berjalan tanpa koneksi yang kuat.

\section{Isu Keamanan Data}

Keamanan data menjadi hal yang penting, karena data dan resource berada disisi provider. Walau provider menjamin keamanan data yang tersimpan, tetapi segala kemungkinan kehilangan data dapat saja terjadi. [2] Untuk mengatasi isu keamanan, dalam SLA perlu didefinisikan security level data dalam SaaS. [12].

Tabel 1. Contoh security level data dalam SLA SaaS

\begin{tabular}{|c|c|c|}
\hline \multicolumn{2}{|c|}{ Security Level } & Definition \\
\hline \multirow{4}{*}{$\begin{array}{l}\text { A:Fully } \\
\text { Autonomous } \\
\text { Control }\end{array}$} & A4 & Tenant deployment \\
\hline & A3 & Independent Physical Machine \\
\hline & $A 2$ & Third-part Security Services \\
\hline & $A 1$ & Tenant controlled Virtual Machine \\
\hline \multirow{3}{*}{$\begin{array}{l}\text { B:Partial } \\
\text { Autonomous } \\
\text { Control }\end{array}$} & B3 & Client Encryption \\
\hline & $B 2$ & Tenant Encryption of the Server \\
\hline & $B 1$ & Vendor Encryption of the Server \\
\hline \multirow{4}{*}{$\begin{array}{l}\text { C:Fully } \\
\text { Commissioned } \\
\text { (Only } \\
\text { DBMS } \\
\text { Technology) }\end{array}$} & C4 & DBMS Isolation \\
\hline & C3 & Database Instance Isolation \\
\hline & C2 & Schema Isolation \\
\hline & C1 & $\begin{array}{l}\text { Shared Table, DBA and } \\
\text { Management separated } \\
\text { authorization }\end{array}$ \\
\hline \multicolumn{2}{|l|}{ D:Public Security } & others \\
\hline
\end{tabular}

Dasar untuk mengembangan sistem keamanan cloud computing harus didasarkan beberapa prinsip keamanan yaitu [9] :
- Kerahasiaan: pencegahan pengungkapan informasi yang tidak sah yang mungkin sengaja atau tidak sengaja mengacu pada kerahasiaan 
- Integritas: konsep cloud integritas informasi didasarkan pada dua prinsip Pencegahan modifikasi data dari pengguna yang tidak sah dan mencegah modifikasi yang tidak sah dari data dengan pengguna yang berwenang.

- Ketersediaan: prinsip ini menjamin ketersediaan data dan sumber daya cloud computing bila diperlukan.

- Otentikasi: hal ini mengacu pada proses pengujian identitas pengguna dan memastikan bahwa pengguna tersebut adalah pengguna yang sah.

- Otorisasi: hal ini mengacu pada hak istimewa yang diberikan kepada individu atau proses untuk memungkinkan mereka untuk mengakses setiap data dan sumber daya komputasi

- Akuntabilitas: hal ini terkait dengan konsep di mana orang tidak dapat menyangkal dari kinerja dari suatu tindakan. Ini menentukan tindakan dan perilaku individu dalam cloud system.

3. Fitur yang terbatas

Karena sistem Saas diakses secara web based, fitur yang dimiliki terbatas dibandingkan aplikasi berbasis desktop.

\section{KESIMPULAN}

1. Business Intelligence

menawarkan solusi bisnis untuk menganalisa data dan memungkinkan suatu perusahaan untuk mengambil keputusan untuk meningkatkan keuntungan dan kinerja bisnis.

2. Untuk mengatasi mahalnya implementasi BI, dapat menggunakan konsep SaaS cloud computing dimana layanan perangkat lunak disediakan oleh penyedia layanan melalui internet.

3. Suatu perusahaan sebelum mengimplementasikan $\mathrm{BI}$ berbasis SaaS, perlu mengetahui beberapa parameter evaluasi untuk penyedia layanan sebagai bahan pertimbangan. Selain itu juga perusahaan harus mengetahui kelebihan dan kekurangan sistem BI berbasis SaaS cloud computing.

\section{DAFTAR PUSTAKA}

[1] A. Anasuya Threse Innocent, "Cloud Infrastructure Service Management - A Review', in Cloud Infrastructure Service Management - A Review. Vol 9. IJCSI Press.2012

[2] Anita Kumari Nanda and Brojo Kishore Mishra, "Privacy and Security issues in Cloud Computing" in International Journal of Advanced Computer Research. Vol. 2. Association of Computer Communication Education for National Triumph (ACCENT). 2012

[3] Chekfoung Tan, Kecheng Liu and Lily Sun, "A design of evaluation method for SaaS in cloud computing" in Journal of Industrial Engineering and Management. Vol 6. OmniaScience \& Universitat Politècnica de Catalunya. 2013

[4] Gurudatt Kulkarni, "Cloud ComputingSoftware as Service" in International Journal of Cloud Computing and Services Science . vol 1. Insititute of Advanced Engineering and Science (IAES).2012

[5] Iwan Sofana, "Cloud Computing : Teori dan Praktik". Informatika bandung. 2012

[6] Jaroslav Jandos, "On Business Intelligence SaaS solution",in Systémová Integrace, vol 19. Czech Society for Systems Integration. 2012

[7] K C Gouda,Sambeet Kar and Rohan Patra, "Cloud Computing: What, How and Why" in International Journal of Engineering Trends and Technology. Vol 4. Seventh Sense Research Group Journal. 2013 
[8] Manfaat Komputasi Awan (http://id.wikipedia.org/wiki/Komputasi a wan) diakses pada tanggal 8 November 2013

[9] R. Charanya,M.Aramudhan,K. Mohan and S. Nithya, "Levels of Security Issues in Cloud Computing", in International Journal of Engineering and Technology. Vol 5. Engg Journals Publications. 2013

[10] Willem J.J. Thompson and Jakobus S. van der Walt, "Business intelligence in the cloud" in South African Journal of
Information Management. Vol 12. AOSIS OpenJournals.2010

[11] W. Torbacki, "SaaS - direction of technology development in ERP/MRP systems" in Archives of Materials Science and Engineering . Vol 32. International OCSCO World Press. 2008

[12] Yongjing $\mathrm{A}$. Li and Jiang B. Wu, "An SLA based SaaS Security Level", in TELKOMNIKA : Indonesian Journal of Electrical Engineering. Vol 11. Institute of Advanced Engineering and Science. 2013 